then will the tension of the cord by which it is suspended at this lower point of oscillation be just twice as great as when the pendulum is hanging at rest. This law may be tested by as many examples as the reader pleases. I shall propose two. Suppose a pendulum two feet long drawn up the arc of its circle, until its perpendicular height is one-half its own length; in oscillating it will descend one foot in perpendicular height. Now it is known from the laws of falling bodies, that in falling freely one foot perpendicular height, either in the line of direction, or on an inclined plane, or in a curve as of a pendulum, it will acquire a velocity of eight feet per second, and according to the rules mentioned above, if a body moves in a circle four feet in diameter, with a velocity of eight feet per second, its centrifugal force will just equal gravity. Suppose now the pendulum is eight feet long, and let it be drawn till it is four feet above a line drawn horizontally through the lowest point of the curve. Now this pendulum moves in an arc of a circle which is sixteen feet in diameter, and at its lowest point, according to the laws of falling bodies, its velocity is 16 feet per second, and with such a velocity, and such a circle, its centrifugal force will be found to be equal to gravity.

TO THE EITTOR OF THE JOURAAL OF TIE FRAXKIN INSTITUTE.

\title{
Description of an improvement in the mode of Balancing Mill
}

\section{Stones.}

SIr,-I offer the following improvement for your consideration, and if you think it worthy, you will please publish it in the Journal of the Franklin Institute. It consists of an alteration in the balance rine and driver, for balancing the running mill stone, obviating the necessity of taking up the stone to remove the rine, and afterwards adjusting the driver so that each prong shall have its full bearing; which improvement will also obviate the necessity of taking out the spindle to adjust and fix the rine and driver as heretofore.

I take a common three pronged balance rine, such as is commonly used, then I rivet, or otherwise secure, a three-cornered box on the under side of the top of said rine, so that each corner nay rest on the under side of each prong. On each side of this box I fix a set screw, to act on a small block of iron, stee!, or other metal, with a centre hole punched in it to admit of the cock head, or upper end of the spindle to rest in. This small block, by working the screws, will move the running stone, and admit of balancing it on the bead of the spindle to any nicety; after the runner is well balanced $I$ apply a suficient force to the wallower on the spindle to bring up the driver to its bearing. Then $l$ take a common three-pronged driver, and fix each prong askew, so as to stand square with the prongs of the rine on the driving side, then the prongs being no longer than the size of the eye of the mill stone, and when fixed on the spindle the lower side of driver and rine being of an equal distance from the face of the bed stone, I insert, through the driver, on each prong, a set screw to

Vol. IX.-No.1.-JANuary, 1832. 
work against each prong of the rine, and to set the said screws. After the runner is well balanced, I apply a sufficient force to the wallower, on the spindle, to bring up the driver to its bearing; then, with a wrench, I screw up the screws that are wanting to come up to the prong of the balance rine, each to a full bearing, so, as I have before stated, that the runner can be justly balanced, and the driver set to its proper bearing, without any cause of taking out the spindle. I have had one in operation some time, on the above principle; it more than answers $m y$ anticipations.

Yours, respectfully, Dantel Lamb.

Almonisson Mills, near Woolbury, N. J. July, 1831.

FOR THE JOURKAL OF THE FIANKIIN INSTYTUTH.

Practical Observations on the good and bad properties of the colou's used by artists. By Joshua Shaw.

Philadelphia, December 28, 1831.

Sra,-Having, in the way of my profession, and by long experi-ence and practical experiment, made myself acquainted with the good and bad qualities of the colours in general use with artists, I am inclined to believe that the results, if male public, would be found of much interest to the profession, as well as to connoisseurs and lovers of the art in general; and believing the Journal of the Franklin Institute to be a useful and legitimate channel through which to furnish the information, $I$ submit the first of a series of remarks, or essays, which I have in contemplation, to your inspection, and which, if approved of, you will please to lay before your readers. You are not to consider my observations as the result of chemical experiment in the laboratory, of which an artist, generally speaking, can be expected to know but little; about as much, perhaps, as a chemist generally knows of painting. I pretend to very little knowledge of the art of manufacturing colours, and shall confine myself to their application upon canvass, their disposition to change, or such other qualifications as may render them valuable or otherwise. My limited knowledge of science as applied to chemistry, or to books, does not enable me to say whether $I$ am in the track of any predecessor or not; but it is a fact as plain to me as noon day, that there is an unaccountable difference between the productions of the ancient and modern artists; I speak with reference to colours themsel ves, and the modes of their application, without the most distant idea of contrasting those merits which belong to composition or design, for in this respect, the balance is certainly with the present generation, notwithstanding any thing which may be said to the contrary by the affected babbling connoisseur, who in every age has been the same dissatisfied malcontent, decrying living merit.

I shall commence with remarks on blues, and the following, to- 